\title{
Mutations in the SPINK1 gene in idiopathic pancreatitis Italian patients
}

\author{
Macarena Gomez-Lira*,1, Deborah Bonamini ${ }^{1}$, Carlo Castellani ${ }^{2}$, Lorenza Unis ${ }^{3}$, \\ Giorgio Cavallini ${ }^{4}$, Baroukh Maurice Assael ${ }^{2}$ and Pier Franco Pignatti ${ }^{1}$
}

${ }^{1}$ Section of Biology and Genetics, Department of Mother and Child, Biology and Genetics, University of Verona, Verona,
Italy; ${ }^{2}$ Cystic Fibrosis Center, Ospedale Civile Maggiore, Verona, Italy; ${ }^{3}$ Transfusional Center, Ospedale Bussolengo,
Bussolengo, Italy; ${ }^{4}$ Department of Surgical and Gastroenterological Sciences, University of Verona, Verona, Italy

Idiopathic chronic and acute recurrent pancreatitis (IP) have been associated with mutations in the cystic fibrosis transmembrane conductance regulator (CFTR) gene. Mutations in the serine protease inhibitor Kazal 1 (SPINK1) have been described in some idiopathic chronic patients and it has been suggested that mutations in this gene could be responsible for a loss of trypsin inhibitor function. In this study, the $5^{\prime} U T R$ region, and the four exons and exon-intron boundaries of the SPINK1 gene in 32 IP patients have been analyzed. Three IP patients (9.3\%) and one control/100 carried the N34S mutation of the SPINK1 gene (Fisher's exact test, $P=\mathbf{0 . 0 4 4 )}$. No other mutation that could be associated with an altered function of the SPINK1 protein was observed. The N34S mutation was present in two patients who carried the CFTR-IVS8 5T variant and in one who carried the L997F variant in the CFTR gene. The association of SPINK1 with CFTR gene mutations in IP patients is statistically significant (3/32 IP cases and 0/100 control individuals carrying mutations in both genes; Fisher's exact test $\boldsymbol{P}=0.01$ ).

European Journal of Human Genetics (2003) 11, 543-546. doi:10.1038/sj.ejhg.5200989

Keywords: SPINK1 gene; CFTR gene; mutations; idiopathic pancreatitis

\section{Introduction}

Chronic pancreatitis (CP) is a continuing or relapsing inflammatory disease of the pancreas. $\mathrm{CP}$ follows recurrent attacks of acute pancreatitis with all of the common complications of $\mathrm{CP}$, including unrelenting pain, parenchymal and ductal calcifications, duct distortion, fibrosis, maldigestion, and diabetes mellitus. The etiological factor of about one-third of chronic and acute recurrent pancreatitis patients is unknown and this group of patients is classified as suffering from idiopathic pancreatitis (IP). Mutations of the cystic fibrosis transmembrane conductance regulator (CFTR) gene have been associated with IP. ${ }^{1-4}$ Active trypsin is inhibited by trypsin

*Correspondence: Dr M Gomez-Lira, Dip. Materno Infantile e di BiologiaGenetica, Sezione Biologia-Genetica, Università di Verona, Strada Le Grazie 8, 37134 Verona, Italy. Tel: +39 045 8027674;

Fax: +39 045 8027180; E-mail: macarena.gomez-lira@univr.it

Received 11 October 2002; revised 11 February 2003; accepted 13 February 2003 inhibitors as serine protease inhibitor Kazal type 1 (SPINK1), and when trypsin activity exceeds the inhibitor effect of SPINK1 it will continue to activate trypsinogen and other zymogens, leading to autodigestion of the pancreas and pancreatitis. Mutations in the SPINK1 gene have been reported in hereditary and idiopathic acute and chronic pancreatitis. ${ }^{4-7}$ Witt et $a l^{5}$ reported that 22 out of $96 \mathrm{CP}$ patients carried a SPINK1 mutation and that 18 of them carried a missense mutation in codon 34 (N34S). Pfützer $e t a l^{6}$ found that 26 out of 57 IP patients carried a SPINK1 mutation and that 23 of them carried the N34S, confirming the association of this mutation with $\mathrm{CP}$ and postulating that alterations in the SPINK1 can act as a disease modifier gene in this pathology. Audrézet $\mathrm{et}^{\mathrm{al}} \mathrm{l}^{7}$ demonstrated that four out of $39 \mathrm{IP}$ cases carried the N34S mutation in the SPINK1 gene.

The aim of this study was to search for mutations in the SPINK1 gene in association with susceptibility to IP in Italian patients and to study the possibility of a 
synergistic effect between SPINK1 and CFTR gene mutations in IP.

\section{Patients and methods \\ Cases and controls}

The population under study consisted of 32 IP Italian subjects (18 males, 14 females, mean age 34.6 years, range 7-59 years), suffering from either idiopathic chronic pancreatitis (17) or recurrent acute pancreatitis (15). The criteria for diagnosis were as follows: for idiopathic recurrent pancreatitis, multiple episodes of usually clinical mild pancreatitis in the absence of the etiological factors most commonly associated with pancreatitis such as colelithiassis, alcohol abuse, pancreas divisum, hypercalcemia, dyslipidemia and viral infections; and for idiopathic chronic pancreatitis: progressive pancreatic inflammatory disease characterized by irreversible morphological changes and typically causing pain and/or permanent loss of function, where none of the possible causes previously mentioned in the other definitions had been detected. A total of 50 control individuals from the same Italian population were analyzed in this study. Mutation N34S was tested in a total of 100 control individuals. The patients had been previously analyzed for mutations in the CFTR gene. ${ }^{8,9}$

\section{DNA extraction and analysis}

DNA was extracted from peripheral blood leukocytes by standard procedures.

Mutation N34S of the SPINK1 gene was detected by PCR with modified primers that produce a restriction site during in vitro amplification (RG-PCR) ${ }^{10}$ using forward primer 5'CAATCACAGTTATTCCCCAG3', and modified reverse primer 5'TGGTGCATCCATTAAGTGCA3' which creates a restriction site for endonuclease Bsp1286 I when allele $34 \mathrm{~S}$ is present. Digestion products were analyzed by $8 \%$ acrylamide gel electrophoresis.

The $5^{\prime} \mathrm{UTR}$ region, the four exons and the exon-intron boundaries of the SPINK1 gene were amplified as described $^{11}$ and denaturing gradient gel electrophoresis (DGGE) analysis of the amplified fragments was performed. Amplified fragments showing an altered migration pattern were directly sequenced using the BigDye terminator Cycle Sequencing kit (Perkin-Elmer) on a 377 ABI PRISM sequencer.

\section{Results and discussion}

Mutation N34S was tested in 32 IP, and 100 control individuals. The mutation was present in three IP patients, one of whom was homozygous, and in one control individual (Fisher's exact test, $P=0.044$ ) (Table 1).

The four exons and exon-intron boundaries, and the 5 'UTR region of the SPINK1 gene were screened for sequence variations by DGGE analysis in 32 cases of IP, and in 50 control individuals. In the $5^{\prime} \mathrm{UTR}$ region, polymorphism $-253 \mathrm{~T}>\mathrm{C}$ and the $-41 \mathrm{G}>\mathrm{A}$ variant were found. The common polymorphism $-253 \mathrm{~T}>\mathrm{C}$ was present in both groups with similar frequencies and the $-41 \mathrm{G}>\mathrm{A}$ variant was present in one IP patient only. In IVS1, variant $-37 \mathrm{~T}>\mathrm{C}$ was observed in three IP patients, and it was in linkage disequilibrium with mutation N34S in exon 3. Beside the N34S mutation, we found the following in exon 3 and boundaries: variant $174 \mathrm{C}>\mathrm{T}(\mathrm{C} 58 \mathrm{C})$ in one IP patient, variants IVS2 $-23 \mathrm{~A}>\mathrm{T}$ in two controls, and a novel sequence variant IVS3+12T $>\mathrm{G}$ in one IP patient. In exons 1 and 4 and their exon-intron boundaries, no sequence alteration was observed. All the DNA variants detected in this study as well as their distribution in both study groups are summarized in Table 2.

Four sequence variations were found in IP patients, and of these only the N34S mutation, which was present in three patients $(9.3 \%)$, has previously been considered as being associated with IP. This result is similar to that reported by Audrézet $e t a l{ }^{7}$ who reported the presence of the N34S mutation in $10 \%$ of ICP patients, and by Ockenga et al $^{12}$ who reported a similar prevalence of SPINK1 mutations in a cohort of adult IP patients. A higher frequency of SPINK1 mutations was described by Witt et $a l^{5}$ and by Pfützer et $a l^{6}{ }^{6}$ where the frequency of N34S in CP patients was 18.75 and $40.3 \%$, respectively.

In this study, no other sequence alteration was observed that could be associated with an altered function of the SPINK1 protein. The $-41 \mathrm{G}>\mathrm{A}$ variant, which was present in one IP and in no control individual, has been discussed by Audrézet et $a l^{7}$ as having a possible role in transcription efficiency of the protein. However, it was also present in

Table 1 Mutations and polymorphisms in the SPINK1 gene and distribution among IP, and controls individuals

\begin{tabular}{|c|c|c|c|}
\hline Location & $\begin{array}{l}\text { Sequence } \\
\text { variation }\end{array}$ & IP & Controls \\
\hline $5^{\prime}$ UTR & $\begin{array}{l}-253 \mathrm{~T}>C \\
-41 \mathrm{G}>\mathrm{A}\end{array}$ & $\begin{array}{l}11 / 32 \\
1 / 32\end{array}$ & $16 / 50$ (3 hom) \\
\hline Exon 1 & - & - & - \\
\hline $\begin{array}{l}\text { Exon-intron } \\
\text { boundary }\end{array}$ & - & - & - \\
\hline Exon 2 & & - & - \\
\hline $\begin{array}{l}\text { Exon-intron } \\
\text { boundary }\end{array}$ & IVS1-37T >C & $3 / 32$ (1 hom) & - \\
\hline Exon 3 & $\begin{array}{l}\text { N34S } \\
174 \mathrm{C}>\mathrm{T}(\mathrm{C} 58 \mathrm{C})\end{array}$ & $\begin{array}{l}3 / 32 \text { (1 hom) } \\
1 / 32\end{array}$ & $1 / 100$ \\
\hline \multirow{2}{*}{$\begin{array}{l}\text { Exon-intron } \\
\text { boundary }\end{array}$} & IVS2-23A>T & - & $2 / 50$ \\
\hline & IVS3+12T $>G^{a}$ & $1 / 32$ & - \\
\hline Exon 4 & - & - & - \\
\hline $\begin{array}{l}\text { Exon-intron } \\
\text { boundary }\end{array}$ & - & - & - \\
\hline
\end{tabular}

${ }^{a}$ Novel polymorphism; hom: homozygous. 
Table 2 Analysis of mutations in CFTR and SPINK1 mutations in ICP patients

\begin{tabular}{|c|c|c|}
\hline IP patient & $\begin{array}{c}\text { CFTR gene } \\
\text { sequence variation }\end{array}$ & SPINK1 gene mutations \\
\hline 1 & F508del, L997F & - \\
\hline 2 & F508del & - \\
\hline 3 & $2789+5 G>A$ & - \\
\hline 4 & F508del & - \\
\hline 5 & R1162X & - \\
\hline 6 & F508del & - \\
\hline 7 & R553X & - \\
\hline 8 & F508del; 3878delG & $174 \mathrm{C}>\mathrm{T} ;-41 \mathrm{G}>\mathrm{A} ;-253 \mathrm{~T}>\mathrm{C}$ \\
\hline 9 & $3849+10 \mathrm{KbC}>\mathrm{T}$ & - \\
\hline 10 & 5T; L997F; S1235R & - \\
\hline 11 & L997F & N34S, IVS1 -37T >C \\
\hline 12 & $5 T$ & - \\
\hline 13 & $5 T$ & N34S, IVS1-37T >C \\
\hline 14 & - & - \\
\hline 15 & $5 T$ & 34S hom; IVS1-37C hom \\
\hline 16 & $5 T$ & - \\
\hline 17 & D614G & - \\
\hline 18 & - & - \\
\hline 19 & - & - \\
\hline 20 & R31C & - \\
\hline $21-31$ & - & - \\
\hline 32 & - & IVS3+12T > G \\
\hline
\end{tabular}

hom: homozygous.

3/190 control individuals in the study by Pfützer $e t a l,{ }^{6}$ so its relevance in IP remains to be determined. Interestingly, the N34S mutation was present in two patients who carried the $5 T$ variant and in one who carried the L997F variant in the CFTR gene (Table 2). The patients carrying one CFTR gene and one SPINK1 gene mutation had no family history of IP. No relatives were available for a segregation study of the mutations. The $5 T$ variant of the CFTR gene is one of the three known alleles with a variant number of thymidines $(5,7$ or 9$)$ in a polythymidyl tract (T-tract) of the acceptor splice site in intron 8 . The variant $5 T$ is associated with low amounts of normally processed mRNA $^{13}$ and, although this allele does not cause CF, it can modify the phenotypic effect of other mutations. ${ }^{14}$ It can be hypothesized that the added action of a lower level of correctly processed CFTR gene product, together with an altered function of the SPINK1 gene product, could have a deleterious effect upon the pancreatic phenotype. A high frequency of the L997F mutation of the CFTR gene has been described in our cohort of IP patients ${ }^{8}$ and it has been postulated that this mutation, together with other CFTR gene mutations, can cause IP as an atypical, monosymptomatic form of CF. As with the $5 T$ variant, it can be hypothesized that the L997F mutation combined with a SPINK1 mutation can have a synergistic effect upon the development of IP. IP patients carrying a SPINK1 mutation as well as a CFTR gene mutation have also been reported by Witt $e a^{15}$ as unpublished data. Noone $e t \mathrm{al}^{4}$ reported nine out of $24 \mathrm{CP}$ patients carrying the N34S SPINK1 gene mutation. Three of these patients carried the SPINK1 mutation together with a CFTR mutation: two carrying the $5 T$ variant in the CFTR gene, and one carrying two CFTR mutations (F508del and $\mathrm{H} 117 \mathrm{H}$ ). In three other patients carrying the N34S mutation, the authors could not exclude the presence of CFTR rare mutations as only the common CFTR gene mutations were screened. Ockenga et $a{ }^{12}{ }^{12}$ revealed double heterozygosity for CFTR Y1092X mutation and SPINK1 R65Q mutation, not only in a patient but also in his unaffected relatives, indicating that other genetic or environmental factors are needed to develop PI. However, the possible relevance of the novel SPINK1 gene mutation R65Q in IP is still unclear.

The frequency of double heterozygotes for SPINK1 and CFTR gene mutations among IP patients compared with control individuals is significantly higher (3/32 IP, 0/100 controls, Fisher's exact test $P=0.013$ ). The presence of patients who carry mutations at the two genes suggests that epistatic interactions in trans-heterozygotes may contribute to disease pathogenesis. The distribution of SPINK1 mutations in IP patients was not homogeneous, 0/10 patients carrying a CF causing mutation, $3 / 7$ carrying a CFTR variant and $0 / 15$ carrying no CFTR gene variant ( $\chi^{2}$ after permutation $P=0.037$ ). Severe CFTR mutations were not identified in this study, possibly because of the low number of observations. Our observation suggests a possible interaction of CFTR and SPINK1 gene variants in determining IP.

\section{Acknowledgements}

This work was supported by the Italian Ministry of University and Research, Italian Ministry of Health CF Project Law 548/93 and National Project for Standardization and Quality Assurance in Genetic Testing Law 502/92.

\section{References}

1 Cohn JA, Friedman KJ, Noone PG, Knowles MR, Silverman LM, Jowell PS: Relation between mutations of the cystic fibrosis gene and idiopathic pancreatitis. N Engl J Med 1998; 339: 653-658.

2 Sharer N, Schwarz M, Malone G et al: Mutations of the cystic fibrosis gene in patients with chronic pancreatitis. $N$ Engl J Med 1998; 339: 645-652.

3 Castellani C, Bonizzato A, Rolfini R, Frulloni L, Cavallini GC, Mastella G: Increased prevalence of mutations in the cystic fibrosis gene in idiopathic chronic and recurrent pancreatitis. Am J Gastroenterol 1999; 94: 1993-1995.

4 Noone PG, Zhou Z, Silverman ML, Jowell PS, Knowles MR, Cohn JA: Cystic fibrosis gene mutations and pancreatitis risk: relation to epithelial ion transport and trypsin inhibitor gene mutations. Gastroenterology 2001; 121: 1310-1319.

5 Witt H, Luck W, Hennies HC et al: Mutations in the gene encoding the serine protease inhibitor, Kazal type 1 are associated with chronic pancreatitis. Nature Genet 2000; 825: 213-216.

6 Pfützer RH, Barmada MM, Brunskill APJ et al: SPINK1/PST1 polymorphisms act as disease modifier in familial and idiopathic chronic pancreatitis. Gastroenterology 2000; 119: 615-623. 
7 Audrézet MP, Chen J-M, Le Maréchal C et al: Determination of the relative contribution of three genes: the cystic fibrosis transmembrane conductance regulator gene, the cationic trypsinogen gene, and the pancreatic secretory trypsin inhibitor gene - to the etiology of idiopathic chronic pancreatitis. Eur J Hum Genet 2002; 2: 100-106.

8 Gomez-Lira M, Benetazzo MG, Marzari MG et al: High frequency of cystic fibrosis transmembrane regulator mutation L997F in patients with recurrent idiopathic pancreatitis and in newborns with hypertrypsinemia. Am J Hum Genet 2000; 66: 2013-2014.

9 Castellani C, Gomez-Lira M, Frulloni L et al: Analysis of the entire coding region of the cystic fibrosis transmembrane regulator gene in idiopathic pancreatitis. On line Citation: Human Mutation, Mutation in Brief \#436, (2001) On Line. Print citation: 18: 165-166.

10 Gasparini P, Bonizzato A, Doginini A, Pignatti PF: Restriction site generating polymerase chain reaction (RG-PCR) for the probeless detection of hidden genetic variations: application to the study of some cystic fibrosis mutations. Mol Cell Probes 1992; 6: 1-7.

11 Chen J-M, Bernard M, Audrezet MP, Ferec C: Mutational analysis of the human pancreatic secretory trypsin inhibitor (PST1) gene in hereditary and sporadic chronic pancreatitis. J Med Genet 2000; 37: 67-69.

12 Ockenga J, Dörk T, Stuhrmann M: Low prevalence of SPINK1 gene mutations in adult patients with chronic idiopathic pancreatitis. J Med Genet 2001; 38: 243-244.

13 Chu CS, Trapnell BC, Curristin S, Cutting GR, Crystal RG: Genetic basis of variable exon 9 skipping in cystic fibrosis transmembrane conductance regulator mRNA. Nat Genet 1993; 3: 152-156.

14 Kiesewetter S, Macek Jr M, Davis C et al: A mutation in CFTR produces different phenotypes depending on chromosomal background. Nat Genet 1993; 5: 274-278.

15 Witt H, Hennies HC, Becker M: SPINK1 mutations in chronic pancreatitis. Gastroenterology 2001; 120: 1060-1061. 